\title{
Memoria, lugares y cuerpos
}

\author{
Maya Aguiluz Ibargüen \\ Centro de Investigaciones Interdisciplinarias en Ciencias y Humanidades (CEIICH) \\ Universidad Nacional Autónoma de México (UNAM)
}

aguiluz@servidor.unam.mx

\begin{abstract}
Resumen
Esta ponencia fue elaborada siguiendo uno de los cursos en el que los cuerpos y la memoria se encuentran mutuamente implicados. El lugar aparece desde el principio en-medio de ambos términos, sin embargo tal conexión es posible porque ninguno de los dos, queda exento de la inscripción cultural en tanto ambos -cuerpo y lugar- son realidades espaciales. Se considera aquí que el cuerpo humano muestra cómo trabaja la memoria social y cómo ese artefacto paradójico, tan simbólico como precultural, participa como memoria corporizada y cuerpos de la memoria resignificando tanto en ausencia, cuando ha sido suprimido o desaparecido, como cuando está presente.
\end{abstract}

Palabras clave: Espacio; Memoria; Lugar de la memoria; Cuerpo-memoria

\section{En el espacio del cuerpo: punto de imbricaciones.}

El cuerpo humano es el terreno de cuestionamiento, del goce y la marca; de la culpa; objetivación de lo social, de sus jerarquías y diferencias; ha sido objeto de experimentación de los saberes de antaño como de las más sofisticadas innovaciones científicas y biotecnológicas; a lo largo de la historia de la humanidad, el cuerpo como cifra de todos los poderes, es descubierto como medida de su eficacia: con ese propósito se ha preguntado ¿hasta qué punto puede llegar la maleabilidad humana usando la represión, la tortura y exterminio? ¿Hasta dónde el sistema sensorial de los cuerpos soportará la ingesta de toxinas, las inversiones térmicas, los rayos ultravioletas? ¿La creciente búsqueda de sentido serán soportadas por el reencantamiento cultural, la fragmentación de la fe vía salidas espirituales, esotéricas, religiosas ...?

Estos cuerpos simultáneamente naturaleza/unidad biológica y cultura/unidad simbólica; objetos de culto, de lucro y tráfico. Son también espacio de la vivencia, goce y de las emociones, tanto las emociones públicas, aquellas socialmente reconocibles, como las otras, emociones silentes, escondidas porque quedaron resguardadas por el proceso de la civilización que Norbert Elias asoció con la contención emotiva y la pacificación de los espacios sociales (que no era más que el surgimiento del estado nacional y la micro-colonización del interior y el sí mismo) como posibilidad de instaurar un orden social y moderno (tendencialmente no violento). 
Los cuerpos son último reducto donde se perciben y padecen en diversos grados la explotación, la humillación y la miseria, de acuerdo al punto del tramado social donde se sitúe. En tanto que espaciolugar, el cuerpo indica; parece hablar desde sí porque registra los malestares; se vuelve un extraño para sí cuando percibe los desequilibrios y -cuanto más- el paso del tiempo. Día a día el cuerpo se nos ofrece acompañado de las señales de cambios irreversibles, de su propio envejecimiento. La reflexión corporal es pues la lectura-del-aviso, pero avisos que tímidamente aparecen siendo asomos de vulnerabilidad, sensaciones de dolor, sentimientos de miedo y temor que comunican sin afirmarse siempre como nudo de sentido de las sendas de acción. Las señales corporales reducidas a meros signos de una superficie a ser leída (a ser diagnosticada) o a funcionar como pautas de la conectividad de incontables flujos comunicacionales delatan la réplicante permanencia de una vieja partición moderna, la del dualismo mente-cuerpo traducida por la frontera espacial interior-exterior, no porque no habría sufrido alteraciones la noción de una racionalidad de la acción con arreglo a certezas estables, sino porque sea cual fuere el contenido de esa interioridad directriz, el cuerpo sigue indicando "algo separado del auténtico sí mismo (self) -sea éste concebido como alma, mente, espíritu, creatividad, libertad....- y algo que socava el mejor esfuerzo del self. (Bordo, 2003 [1993]: 45; trad. Propia). De manera que cuestiones tan diferentes surgidos de fenómenos como la anorexia y la obesidad coexisten en el desbordamiento e inestabilidad de la identidad y la construcción de la personalidad contemporáneas; en este par de casos citados, el primer fenómeno asociado ya a fines del siglo XIX con las presiones de cultura en ascenso de la publicidad, la imagen y el consumo ha pasado a consumarse como extrema control de los deseos, internamente administrados por un sobredemandante "yo" macroregulado mientras el segundo, como la capitulación a los estímulos externos. (Ibíd: 211).

El cuerpo, de cualquiera de estas maneras, se presenta como el espacio persistente por el cual atraviesan las macro regulaciones sociales, asimismo se presenta - de acuerdo con la dimensión capturada por Husserl respecto del "cuerpo vivido"- como el punto persistente al cual todas las relaciones espaciales [derecha/izquierda; adelante/atrás; arriba/abajo, entre otras] aparecen conectadas" (véase Casey, 1997: 217). Con esto quiero remitir a la consideración que permea el espacio de este texto a saber: el cuerpo es un artefacto paradójico que por definición consideraré como:

"[E]lemento de la naturaleza y no de la cultura [...], sin embargo, tanto una entidad biológica como un constructo social y filosófico. Puesto que siente dolor y placer, envejece y muere, el cuerpo físico nunca puede ser objeto de apropiación completa por parte del orden simbólico. Aunque puede ser el 'fundamento de todo simbolismo' [...], el cuerpo es también precultural y prelingüístico." (Payne, 2002 [1998]: 119)

En esa doble faz simultánea, el cuerpo pura fisicalidad como mera representacionalidad, puede mostrar alguna de las vías como la memoria trabaja socialmente -haciéndose y rehaciéndose- en un proceso en el que la memoria corporizada o los cuerpos de la memoria significan a su vez en ausencia, cuando por han sido suprimidos como cuando se vuelven o están presentes.

A modo de puntualizar estas ideas a continuación en el apartado II, me refiero a la delimitación del cuerpo como "lugar de la memoria" como cifra testimonial de acontecimientos pasados, pero también como el dispositivo humano en la evocación específicas memorias asidas a los lugares y los espacios 
sociales; enseguida al considerar que el papel del cuerpo humano en la construcción de la memoria han contribuido las interpretaciones que relevaron la doble presencia del cuerpo como sitio de inscripción histórica y cultural, así como signo diferenciador en sociedades desiguales hago una pausa en la parte III, para remitir a dos de las contribuciones clásicas del siglo pasado. Para terminar intento cuestionar cuáles los desafíos de las memorias sociales, en condiciones actuales en que lo social del cuerpo parece desvanecerse ante el influjo de las imágenes prototípicas de idearios corporales, mientras la condición de vida vivble se diluye en la canalización de la muerte y la espectacularidad de la sociedad tecnologizada.

\section{Cuerpo lugar-refugio de la memoria.}

Nuestros cuerpos hacen las veces de nuestra casa, el hogar primero; son pues el espacio interior que puso por delante Gaston Bachelard, los cuerpos "están en nosotros tanto como nosotros estamos en ellos" (Bachelard, 1975 [1958]: 30) ${ }^{1}$. Con el cuerpo-hogar no solamente edificamos el refugio afectivo y emocional del sí mismo-de nosotros, tomamos el cuerpo como primer reducto contra la alienación (puesto que no es más ese extraño, la materia ajena y desconocida) y contra su objetivación, ese cuerpo reificado que conlleva la sujeción y el abandono de sí.

Cuando en el cuerpo se vive el hábitat personal, también en la esfera corporal está inscrita la memoria: ahí emerge la capacidad de rememorar puesto que las marcas de pasados acontecimientos (las heridas vividas, sentidas, experimentadas que habrá que suturar simbólica, individual o colectivamente) han tenido lugar.

Si consideramos al cuerpo como un "lugar de la memoria", haciendo eco de la frase lieux de mémoire acuñada por el historiador Pierre Nora $^{2}$ ), no sucede lo que en los lugares físicos: monumentos y plazas construidas ya como un eslabón de los discursos patrióticos que acompañaron la estatización de las naciones, tampoco es el sitio sobre el que se colocan pisos de memoria apilamientos que suponen en el fondo ha quedado el rastro de lo que fue: un pasado origen y fuente de la identidad colectiva tal como funcionaron los rituales memoriosos. En ese mismo sentido, el cuerpo humano que invocamos aquí juega las veces de punto partida desde donde se hilvanan recuerdos de vividos y se reinsertan las vidas personales en los cuerpos sociales.

La significación del cuerpo como lugar de memoria conlleva una gran oscilación, como la que condujo a romper con la noción de topografía conmemorativa con que se invistió a ciertos sitios (confiscando así la memoriación); en este movimiento se metamorfosea la idea de cuerpo como "testigo del

\footnotetext{
${ }^{1}$ Si con Poéticas del Espacio (1978 [1958]), Bachelard pasa por la fenomenología, corriente de pensamiento que incorpora la obra de Merleau-Ponty, influido por Bergson y antes por la filosofía de Husserl y Heidegger, con diferentes matices conceptuales, pero de manera distintiva los primeros tres tuvieron "una comprensión corporizada de la memoria, está física y psíquicamente inscrita en nosotros." (Game, 1996: 202)

${ }^{2}$ Les lieux de mémoire, obra en siete volúmenes que dirigió el historiador sobre la historia francesa publicada entre 1984-1992 y que bajo la reflexión de Ricoeur representa la gran oscilación entre la ruptura contra la confiscación de la memoria por la conmemoración a "lo que de insólito implicaba la noción del comienzo", pero en un movimiento que va metamorfoseando los "objetos testigos del pasado" en memoria-patrimonio de una herencia colectiva aprehendida en el presente. Una gran operación también en que "la conmemoriación misma [es] la que se ha metamorfoseado" (Ricoeur, 2003: $528,525,532$ y 535$)$.
} 
pasado" para reinsertarlo en el presente como cuerpo-patrimonio de los sujetos individuales y colectivos. $^{3}$

Que los lugares se constituyen en memoria depende menos de las atribuciones y las propiedades (sobre) impuestas por acciones y voluntades externas que por cierta fuerza ( $y$ voluntad) por rememorar, en un ejercicio de apropiación de historias muchas y multiplicándose (pequeñas vs. la memoria histórica fundida en el relato de los estados nacionales). Los emplazamientos topográficos, los sitios físicos han sido adheridos a las ritualizaciones colectivas por su alcance significativo; porque son "marcas exteriores", "inscripciones" sobre los espacios sociales: el calendarios, una marca del tiempo social; un emblema, identificador ofrecido a la totalidad del grupo (Ricoeur, 2003 [2000]: 529); pero a diferencia, de esos objetos-lugares, el cuerpo en su fisicalidad, "ya sea por la impronta de externalidades o desde un control administrado desde el interior [...] ningún cuerpo puede escapar a la inscripción de la cultura o a sus significaciones generizadas" (Bordo, 2003 [1993]: 212; trad. propia).

Si los espacios físicos, museos, plazas, edificios, museos, etc. han sido aparejados con los grandes archivos de documentos y objetos -muertos- no sólo se debe a la obsesión del saber y el conocimiento moderno por coleccionar y contener la inmensa variedad del mundo real, ha sido también porque la tensión implícita de la memoria, entre el recuerdo y el olvido, generó esa ansiedad complementaria de aquella compulsión: no dejar nada al extravío se tradujo en la necesidad de colocar todo en el plano de la visibilidad, y los seres vivientes o no, que pueden ser vistos han sido antes susceptible de otro orden de manipulaciones, del acopio, la medición, la clasificación y la identidad, en un principio 'nombre', 'cadenas de procedencia' y 'lugar de origen'.

Habría que decir asimismo que esa ansiedad abarcadora tiene por correlato la incansable energía humana que está en la base de rehacer y deshacer lo hecho, así reedificamos los lugares para dar cabida a las contramemorias, ese conjunto de energías sociales que resisten las memorias históricas (oficiales) y que son resultado de la producción de comunidades de memoria (o interpretación) que resignifican el espacio físico y en esa acción producen plurales memorias alternas. El tránsito memoria-lugar tensa un vínculo inevitable, un doblez significante con el que habrá siempre de distinguirse entre sitio físico y lugar, éste preñado de un carácter espiritual, cultural e identitario. Esa otra articulación entre espacio, en sentido amplio y activación del recuerdo depende de la intención actualizada de actores y actrices sociales librando sus batallas contra alguna "verdad" fabricada desde los lugares de enunciación de los poderes.

\footnotetext{
${ }^{3}$ Sigo aquí la reflexión que Paul Ricoeur efectúa con respecto a los "lugares de la memoria" de Nora, noción que representa la gran oscilación entre la ruptura de la asimilación de la memoria por la historia: tomando como polos del movimiento, las fechas que ligan la producción histórica 1984 y 1992, éste se inicia como una operación contra la confiscación de la memoria por la conmemoración terminando en una suerte de vuelta a lo mismo, "lo que de insólito implicaba la noción del comienzo". Sin embargo, lo que en el movimiento oscilatorio se va transformando son los "objetos testigos del pasado" en parte, en todo caso, de una "memoria-patrimonio", en la aprehensión de una herencia colectiva en el presente. Una gran operación en que "la conmemoriación misma [es] la que se ha metamorfoseado" (Ricoeur, 2003 [2000]: 528, 525, 532 y 535)
} 
La tradición memorística tiene una larga procedencia al igual que la memoria y sus dispositivos. En la Grecia antigua, se ligó esa disposición efectuada por los memoriosos con el espacio físico y los cuerpos: cuenta más o menos la leyenda que Simónides de Ceos (556-468 a.C.) estando en un banquete fue llamado a la puerta (por los dioses Cástor y Pólux), al momento de salir un fuerte temblor destruyó la casa, quedando los cuerpos, sin vida, de los comensales bajo los escombres. Simónides, el superviviente se da la tarea de identificar los cadáveres desfigurados e irreconocibles sólo mediante el recuerdo del lugar que ocupaba cada uno durante el banquete: "a partir de esos 'lugares' visualizó mentalmente los rostros característicos de cada persona." (Báez Rubí, 2002: 327 n; véase también, Wacjman, 2001 [1998])

Simónides, por azares del destino, participó menos en el testimonio de lo acontecido, que en el reconocimiento de los sitios particulares que signaron el encuentro de la vida y la muerte. Pero el motivo que reunía a los comensales no es menos significativo, la reunión alrededor de la mesa y no un campo de batalla, por lo cual el ligamen entre los espacios físicos y el poder de memoria es evidente: "en el recuerdo -decía Georg Simmel- el lugar adquiere una mayor fuerza asociativa que el tiempo, porque el lugar tiene carácter sensible"; con acontecimientos desastrosos como en la leyenda o con sucesos menos impactantes el grado de "[...] conmoción sentimental" asociado al lugar lo "constituye [en] el punto de rotación en derredor del cual el recuerdo liga a los individuos [...]" (Simmel, 1986 [1908]: 665; énfasis propio).

De la misma manera en esa imagen de socialidad, que sirvió a Simmel para connotar los espacios, parece importar ese movimiento (aunque giratorio) que enlaza individualidades como el contenido de tal lazo vinculante: el lugar importa puesto que provocó una comunalidad de emociones. Para cerrar la idea con otra imagen: la memoria une tanto por la profundidad de las raíces de una zarzamora como por el aroma y el sabor de sus frutillas. ¿Se trata de simplificar la memoria mediante un artilugio figurativo? Vuelvo al cuerpo. La capacidad de evocación, de asociar hechos y recuerdos atraviesa la completitud de la persona, atestiguar entonces algo acontecido implica la capacidad de articular un pasado sirviéndose del cuerpo por entero, de las reminiscencias de experiencias vividas (y percibidas).

Esa dimensión no-cognitiva, que remite al conjunto desordenado y poco selectivo de impresiones sensoriales, ha formado parte de la historia de los lugares y específicamente en la construcción y segregación espacial: los olores asociados con las multitudes empobrecidas, las prostitutas, los indigentes y marginales, las epidemias y 'los desperdicios' producidos por las ciudades del siglo XIX conformaron un "modo sensorial" particular de las elites y burguesías locales que jugó un papel organizador separando los aromas de muerte, locura, enfermedad y decadencia y dando origen a una "geografía del olfato." (McNaghten y Urry, 1998: 127). Junto con otros temores asociados a la presencia de la muchedumbre, como el miedo al roce y al tocamiento, las sensaciones olfativas y las clasificaciones derivadas de la estigmatización de olores, aromas y diferencias sociales, étnicas, raciales.... permearon tanto los planes urbanos y las políticas públicas de saneamiento y control como el mismo diseño y construcción de "odopaisajes". (McNaghten y Urry, 1998: 127)

Así visto el lugar se confunde en su sentido más amplio con "la marca", esa huella que hace factible la preservación y la legibilidad del pasado; aunque con la modernidad al volverse extensivo y estable el registro escrito, 'leer' supuso que la sucesión de huellas-símbolos-escritura-lectura se asentara como un medio estable de interpretación, una 'fuente' productiva de concierto colectivo y la 
posibilidad de escribir la historia ${ }^{4}$. Desde la antigüedad correspondió a la memoria (en realidad al don de Mnemosyne, la musa portadora de semejante nombre) hacer las veces de la cera sobre la que se graba en relieve una marca, como la de los anillos o los sellos -según rememora Derrida, al Sócrates de Teeteto, para empezar uno de sus no menos famosos textos con el dilema entre la memoria y la historia, la remembranza y la narración, bien signado en los años ochenta (véase Derrida, 1998 [1986]: 17); dilema que más o menos consistía en cuestiones que muy forzadamente esbozo: 'la memoria pertenece al recuento implícito del narrar histórico', 'narrar no es tan sólo secuencia de tiempos, es a su vez acontecimiento en un paisaje ... un algo que ha dejado un rastro' ¿y rastro no es acaso remembranza y no-olvido?'.

La coincidencia del lugar y la marca se desdobla en la vía de la memorización, como registro y recuento de acontecimientos y sucesos -indispensables la datación histórica y la 'memoriación', una forma adverbial indicativa más de una capacidad de surcar el pasado en razón del presente que de arrogan distintos agentes sociales, potenciando la historia (escrita, transmisible y 'oficial') a otras formas narrativas que han sido y son producidas desde los circunloquios, los testimonios, la alegoría y la parodia, la incongruencia aparente entre el decir y el pensar, y las tácticas propias de las otras formas de apropiación y resistencia, fueren orales o escriturarias.

Cuando esta distinción opera en la misma producción de la historia, menos cautiva de la edad de la huella (de la temporalización) que de la procedencia de la marca y por tanto, ha estado más atenta de los espacios, de la especialidad de las historia, desde donde se enuncian discursos y de los lugares de las narraciones, entonces también la noción de memoria como labor producida -como trabajo- ha pasado de igual forma por la imaginación social, esa fuerza que deshace la memoria orientada al presente (un tiempo asido a sus modalidades: presente presente, presente pasado y presente futuro) para materializar su discurso: sólo la memoria que se proyecta, "constituye la presencia del presente" (Derrida, 1998 [1986]: 67-8)

En la proyección de la memoria interviene esa colonización del futuro dependiente del plano real de prácticas sociales que hacen de la imaginación y de la significación de los lugares un recurso. La 'memoriación' es un trabajo, una labor producida en la que se ven involucrados además de éstos, los cuerpos y un arco emocional que dan sentido y carácter a los lugares. Cuando se significan los espacios en efecto se da una determinada representación de los espacios y la consecuente emergencia de los "espacios representados" son también mecanismos de la memoria y constituyen el reservorio activo de los grupos sociales y las comunidades humanas. Si bien es una convención científica el hecho que la "memoria" corresponde más al dinamismo sináptico cerebral en cada

${ }^{4}$ Hannah Arendt recuperó, de manera célebre, la condena platónica al discurso escrito, colocando como fondo de su propia interpretación el sentido del examen socrático:

cualquiera que conoce la debilidad de las palabras, no se arriesgará jamás a organizar pensamientos mediante discursos, y todavía menos a fijarlos en una forma tan rígida como la letra escrita, no debido a una ciega suspicacia frente a lo escrito, fijo y proclive al autoritarismo, sino porque la base de la indagación y el examen del conocimiento es la desconfianza respecto de cualquier doctrina acabada, y una atracción por la prosecución de la búsqueda, más allá de las "palabras", las "definiciones", las "representaciones" y el "conocimiento", (cit. por Joxe, 1999; véase Arendt, [1971] 1995: 118) 
individuo; socialmente hablando, las interacciones entre olvido y recuerdo pasan por la acción colectiva y la intencionalidad política de organizaciones civiles y sociales que disputan el derecho sobre la "memoria colectiva" -un término que en su formulación original de Maurice Halbwachs sancionaba "la integración de la historia en la memoria individual y colectiva ampliada" (Ricoeur, 2003 [2000]: 518). De esto podemos seguir que los rasgos colectivo o individual de la memoria podría continuar distinguiéndose, de principio, como "dos maneras de organización del recuerdo", así también es posible operar la distinción que contrapuntea una "memoria histórica" unificada parte de las funciones, formalizadas como parte de la narrativa del estado-nación, pero también deliberadamente producida y trasmitida dentro de los proyectos pedagógicos nacionales, y, de otra parte la configuración plural de memorias producidas, orales, locales y muchas veces, cortas referidas a acontecimientos recientes (Halbwachs, 1968 [1950]), que lleva a la conclusión de que las obras de múltiples memorias se condensan en lugares donde puede converger mecanismos de memoria colectiva: como memoria-nación, memoria-Estado, memoria-ciudadano ${ }^{5}$ con los mecanismos característicos de la evocación y rememoración individual que parten de sus sentidos y emociones arraigados culturalmente.

\section{Dos giros indispensables del siglo XX.}

Tan complejas y diversas son los debates acerca de la inserción del cuerpo en las reflexiones sociales que las discusiones específicas en relación con la memoria colectiva no ha dejado de lado la pugna entre su lugar como último reducto de la materialidad de los sujetos y personas y el papel del cuerpo como signo y representación en la doble confluencia del "cuerpo como metáfora de lo social y lo social una metáfora del cuerpo." (LeBreton, 2000)

Entre varias evoluciones, en el curso del pasado siglo XX dos giros teóricos -ahora clásicos y estandarizados- incidieron en lo que fue un nuevo tratamiento del cuerpo: 1) el de sitio de inscripción social y discursiva, y 2) el de código de distinción clasista y social.

\section{1) Constitución del sujeto moderno: Yo, cuerpo, inscripción.}

Entre otras construcciones centrales sobre el mundo de saber y la modernidad, Michel Foucault escudriñó el poder moderno dejando de lado su definición clásica como relación efectiva que culmina con la obediencia de unos, ni tampoco atendió demasiado el tema de el uso de medios (de poder) simbólicos y materiales por quienes mandan; en cambio empezó por relevar un aspecto clave: los mecanismos de poder modernos "han tomado a su cargo la vida de los hombres, a los hombres como cuerpos vivientes." (1996: 109)

El análisis foucaultiano del cuerpo $^{6}$, es una prueba de la capacidad productiva del poder y sus dispositivos de disciplinarmiento, control y regulación del cuerpo. De hecho el cuerpo -dice- en todas

\footnotetext{
${ }^{5}$ Algunos de los lugares de memoria rastreados e interpretados por la obra de Nora. (Cit. por Candau, 2002: 57 )

${ }^{6}$ La idea corresponde justamenta a la perspectiva genealógica en la cual la concepción de poder se vuelve más compleja, es la etapa en la que se subraya -como mencionamos más adelante- la mutua dependencia entre saber y poder; la de conceptos como "complejo saber-poder"; "biopoder", etc. Por supuesto el cuerpo del individuo corresponde al mismo tiempo a una identidad escindida, imagen afín a la crítica del hombre moderno.
} 
las sociedades ha estado bajo el control de los poderes más estrictos (1979:136) y se ha constituido como "superficie de inscripciones" sobre él ha operado los más distintos discursos, mecanismos y tecnologías hasta llegar a poseerlo como objeto de la ciencia: en su más íntima interioridad, el cuerpo como conciencia individual, y en su positividad como objeto viviente.

Históricamente Foucault encontró los rastros de la constitución del cuerpo como un objeto que fue adquiriendo significaciones en distintas etapas históricas y diferenciaciones de género y generacionales principalmente en la época clásica del siglo XVIII) se asientan las distinciones entre el cuerpo femenino, el cuerpo del infante, y emerge con claridad la posibilidad de vincular castigo y sanción social con reclusión física y confinamiento panóptico ( antes hasta el siglo XVII, recordaremos el castigo se inflingía como espectáculo público con fines de ejemplaridad, tema que también exploró Durkheim). En fin la importancia de escudriñar la historia del cuerpo, llevó a estabilizar el cuerpo como artefacto con diferentes funciones en el tiempo y como un objeto a regular. Históricamente las estrategias desplegadas por cada dominación disciplinaria variarían de la apropiación absoluta de los cuerpos, durante la esclavitud o las disciplinas ascéticas de tipo monástico -cuyo objetivo fue obtener ganacias e incrementar el dominio sobre el cuerpo (1979:137), hasta la objetivización del cuerpo moderno que funciona en términos de utilidad, eficiencia, obediencia, sobre todo, al menor costo posible (1979: 138 y 136).

Esta síntesis apegada al consenso foucauldiano (a tono con el aniversario de 'la muerte del autor' 1984-2004), ha sido traído al propósito de reiterar como el nexo cuerpo-historia mediante el cual Foucault relevó una doble presencia del cuerpo, por una parte del " cuerpo-objeto fáctico, sobre el que han operado los más distintos discursos, mecanismos y disciplinas hasta producirlo, y por otra parte, del cuerpo-objeto de observación, depositario de la mirada de la muchedumbre y la observancia política, ejemplificado en la condena al suplicio de Damiens llevado al cadalso y desmembrado en el espectáculo público de 1757, con que da comienzo Vigilar y castigar". Quiere esto decir que a la tradición de observancia de la simbología del cuerpo en la cultura occidental, este doblez no siguió "un continuum histórico, sino la presentación de un cuerpo sufriente, situado entre la vida y la muerte, o al borde de éste, un cuerpo que se antepone al discurso." (Aguiluz, 2005).

Poner de relieve la centralidad del cuerpo como dimensión vital y biológica y constituyente del símismo, menos como una estructura especular que como parte indistinta de la normalización de las formas de vida social sujetas a la protección del poder político (a "biopolítica" moderna), condujo a otra conexión, no menos inquietante, hecha evidente en el curso que siguió (la concentración del) derecho del estado moderno para dirimir sobre la vida y la muerte que ha quedado expuesto en las experiencias históricas de los poderes totalitarios y regímenes de facto. "El ingreso de la zoe en la esfera de la polis [no es un hecho excepcional], la politización de la nuda vida como tal, constituye el acontecimiento decisivo de la modernidad" (Agamben, 2003 [1995]: 13) que ha terminado por rutinizarse hasta convertir el cuerpo humano, al ser viviente, en una zona de indistinción entre lo público y lo privado, cuyo laboratorio primero fue el campo de concentración: "Quién era judío en Auschwitz o mujer en bosnia en Omarska, había entrado en el campo no por una elección política, sino por lo que tenía de más privado e incomunicable: su sangre, su cuerpo biológico." (Agamben, 2001 [1996]: 101).

7 "El cuerpo: superficie de inscripciones de los sucesos (mientras que el lenguaje los marca y las ideas los disuelven), lugar de disociación del Yo (al cual intenta prestar la quimera de una unidad sustancial), volumen en perfecto derrumbamiento. La genealogía, como análisis de la procedencia, se encuentra tanto en la articulación del cuerpo y de la historia." (1983:142) 


\section{2) El gusto, las incorporaciones. El cuerpo como codificador de las distinciones sociales.}

Al estudiar las bases sociales del gusto, Pierre Bourdieu en su obra La distinción (2002 [1979]), identificó tres maneras de las clases dominantes para afirmar su distinción respecto de la clase obrera (2002 [1979] : 182 y ss.): la constitución de preferencias en el consumo cultural, alimenticio y de representación (vestido, cuidado de belleza, artículo de tocador, personal de servicio) entre los miembros de fracciones de la clase dominantes (profesionales liberales, industriales y comerciantes) estructuran diferencias internas de acuerdo a variadas prácticas y preferencias de consumo. La dieta de las clases sociales depende de la idea de cuerpo de cada clase y de los supuestos o imaginarios sobre los efectos de la alimentación sobre el cuerpo (fuerza, salud y belleza): entre las clases populares, más atentas a la fuerza del cuerpo (masculino) que a su forma, el consumo se realiza con base en criterios de menor costo y mayor contenido calórico (y nutritivo), mientras que los sectores más privilegiados se inclinarán por alimentoas sabrosos, ligeros, saludables y de bajo contenido en grasas:

"Cultura convertida en natura, esto es incorporada, clase hecha cuerpo, el gusto contribuye a hacer el cuerpo de la clase: principio de enclasamiento incorporado que encabeza todas las formas de incorporación, elige y modifica todo lo que el cuerpo ingiere, digiere, asimila, fisiológica y psicológicamente" (Bourdieu, 2002 [1979]: 188, énfasis mío)

El consumo visto desde la perspectiva cultural, abarca no el consumo de objetos, bienes y mercancías, entidades físicas, sino todas las actividades sociales que in-corporan grupos e individuos: la identidad (cual sea ésta, colectiva, homosexual, de clase, etc.) se construye con relación a tipos de consumo específicos, así la biografía personal (la vida de cada uno), se articula con series de identidades basadas en elementos de género, preferencia sexual, locación geográfica, gustos de clase, musicales, etc. (Bardella, 2002: 83). Con la cultura telemediática del mundo globalizados, es evidente que ciertos modelos de identidad (como la homosexual) se movilizan a través de ciertas "iconografías" de masculinidad y feminidad internacionalizadas que salta a la vista en distintos y distantes paisajes urbanos y las potencialidades de resistencia subcultural se trasforman en "estilo de vida", concepto que enfatiza tanto una diferencia dentro de una cultura como una elección individualizadora e individualizante (que diferencia) frente al cómo se quiere vivir, una elección que finalmente se alinea dentro de los parámetros de las elecciones racionales y un control cognitivo frente al cuerpo individual.

'Posicionalidad y distinción de los cuerpos' fueron dispositivos mediante los que las relaciones sociales e intersubjetivas se in-corporaron. En la cima de la modernidad, el cuerpo y los estándares de belleza basados en el color de la piel, el tamaño del cráneo y la supuesta perfección de los rasgos anatómicos signaron el arribo a un periodo de valorización corporal equiparada al valor económico. Junto con el capitalismo industrial y la economía monetaria, la circulación del dinero, como medida estandarizada de valor (medio de circulación, equivalente general de valor y medida del tiempo de trabajo social) se estandarizó también el cuerpo humano de acuerdo con los paradigmas occidentales: cuerpo heterosexual, blanco, europeo y de clase media. Recordemos que el auge de los discursos seudocientíficos a finales del siglo XVIII, Johannes Lavater y el resurgimiento de la fisiognomía, o la relación entre la superficie física y visible y las condiciones morales internas se 
constituyó en una manera de ver y reproducir distancia social, cuando la corrupción moral guardó una proporción directa con la fealdad; la inteligencia con el tamaño y forma de la nariz .... El cuerpo y sus partes fueron entonces legibles social y científicamente sirviendo, a su vez, como parámetros aplicados sea en el conjunto de la legislación constitutiva de los estados nacionales, o en las legislaciones más particulares.

El alcance que en América Latina tuvieron las investigaciones frenológicas y criminalísticas del antropólogo Cesare Lombroso no solamente llegaron a cruzar los umbrales del siglo XIX en América Latina en lo que vino a constituirse parte de los imaginarios de las elites republicanas y criollas en países altamente diferenciados donde los estudios sobre el tamaño del cráneo entre los nativos tuvieron su corolario en los discursos sobre la violencia instintiva o la inclinación criminal del indígena, bárbaro, incivilizado. De manera similar durante el período comprendido los años treinta hasta aproximadamente los cincuenta, dictaduras centroamericanas, como la de Tiburcio Carías, en Honduras (1933-45), desplegaron medidas y acciones de regulación de la población que "se expresaron a nivel macro en procesos de información-control de la vida y moral cotidiana de los habitantes. Así, se llevaban registros de procedencia, entradas y salidas de hoteles y posadas; consultas y atenciones en centros de emergencias; control estricto de 'meretrices', todo bajo el lema nacional de 'paz, orden y trabajo' [Llegando incluso] al registro del número de extracciones de uñas, extracción de piezas dentales, panadizos, inyecciones, suturas, abscesos, colirios, lavados de oídos, extracción de cuerpos extraños... " (Tábora, Rocío, 2001).

\section{El dezplazamiento del cuerpo en la sociedad moderna global.}

Es indiscutible que desde los más remotos tiempos la idea de que el hombre (sic) o el cuerpo es "'la medida de todas las cosas' fue fundamental en muchas de las corrientes de la filosofía presocrática (Harvey, 1999), una noción que conserva su connotación general, a pesar de su distancia histórica.

Los deslizamientos ocurridos respecto a la significación y la participación de los cuerpos en lo social han complejizado las representaciones binarias que sirvieron a las definiciones modernas. Relaciones, antes mencionadas, cuerpo/alma-mente; experiencia/contexto social; dentro/fuera; sí mismo/alteridad, así como la posición de géneros han pasado a situar la corporalidad como locus de la mediación de distintos procesamientos de la subjetividad, por cuanto una definición actual del 'constructo' y lugar del cuerpo, diría:.

"el cuerpo que se convirtió en cuerpo humano, coincide con la 'forma' y el espacio de una psique, es un cuerpo cuya superficie epidérmica contiene una unidad psicológica, un cuerpo que define los límites de la experiencia y la subjetividad [...] a través de la intervención del otro y en última instancia de un orden simbólico -en tanto lenguaje y orden social." (Grosz, 2002: 298; trad. prop.)

En términos de identidad viró la relación del cuerpo/sí mismo que "surgía" justamente del centro de necesidades, impulsos e instintos, en cuanto centro receptivo o interioridad de la identidad para priorizar la acción pragmática individual, las identificaciones sucedáneas y altamente móviles y los rápidos recambios de 'ensamblados miméticos' que cada sujeto construye.

Aunado a esto se ha llevado al extremo la condición de 'estar o morar en cada espacio social' (ese espacio lleno de interacciones definido por Simmel) por cuanto esto significa tanto que en ellos la 
presentación corporal, en su materialidad sensible anticipa y reconduce al sujeto en su completitud, puesto que el cuerpo trabaja por delante [...] reconoce, no olvida (Thrift, 1996), como a la vez que el cuerpo sea desplazado como artefacto imbricado en relaciones espaciales que deja de importar por su movilidad, sus posiciones en los espacios sociales, su estar y su emplazamiento para importar por sus modalidades de interfaz a través de las TIC (para usar sus siglas, tecnologías de la información y comunicación).

¿Hay en estas experiencias lugar para la memoria? En el segundo caso del cuerpo difuso, ampliado y movilizado mediante la conexión tecnológica, "la memoria regresa [...] a su papel de ser objeto de todo tipo de información en forma de ideas virales" (Hernández, 2003: 210), agregando a su inserción informática de archivo de archivo, su carácter de memoria holográfica, que escribe-y-contiene-todo, mientras que como 'transeúntes' de los flujos espaciales sucede algo similar a la vacuidad de la memoria de que Benjamin asoció con el shock que "el transeúnte sufre en medio de la multitud" dispuesto siempre a la contingencia y al azar como un "jugador": a cada momento el incesante fluir amenaza con adueñarse "de sus cuerpos y sus almas, por lo cual incluso en su fuero íntimo, por fuerte que sea la pasión que los agita, [corren el riesgo de no] obrar más que automáticamente." (Benjamin,1967 [1955]: 26-7) En estos cuerpos-transeúntes la memoria no se ha liquidado por completo, opera simplemente con la misma velocidad de la licuefacción social: está disponible sólo en caso de necesidad pragmática.

Quisiera para finalizar contrastar la modelación de los cuerpos individuados con sobredeterminación de una imaginería mediática con la reaparición de "cuerpos sociales", las multitudes sensibles, hechas cuerpo que cobran presencia también en los circuitos y flujos global-localizados.

Dentro de los circuitos de la industria de la imagen de sí, aspecto nodal de la acelerada totalización de la cultura globalizada, la asimilación del cuerpo a los reciclamientos de la identidad y a la ingente oferta de identificaciones sustitutas desvanece el tipo de referencias localizadas, entre las que destacan las construcciones de las memorias, evidentemente. Las imágenes que quedan expuestas por las industriales culturales, los discursos electrónicos y la producción del sí corresponden a corporizaciones de hombres y mujeres esbeltos, cultivados físicamente, deseables... La efectividad del producto en la producción de la protopersonalidad posmoderna va de la mano con los ritmos acelerados de las mutaciones en la imagen, moda, estilo del "yo" como en las preferencias y consumos de tiempo libre y esparcimiento, los sonidos, los ritmos y fusiones musicales.... Ese despliegue tiene como origen un sofisticado diseño del concepto que tiene como corolario, el producto cultural, generalmente, un icono corporizado. (véase, Kellner, 1995)

Por último quiero referirme a esa configuración global en la que los cuerpos no ingresan a una espiral de mutaciones macroreguladas, como las anteriores, sino que retornan a su condición de 'quedar expuestos' en espacios sociales donde se libran batallas políticas y guerreras. Desde el pasado siglo, tendió a estabilizarse la conciencia de que la escala global comprende no sólo la coexistencia de espacios, tiempos y situaciones, sino y más profundamente -como ha insistido Bauman, la percepción de que todos estamos dentro: estar dentro o fuera no es una cuestión de opciones. La diferencia del adentro y afuera que orientara el sentido básico de movimiento y posición en el espacio participa como una más de las distinciones modernas hoy difusas; a la permeabilidad y constante emplazamiento de linderos, físicos e imaginarios, sigue también la indefinición de esa línea segmentadora espacial. 
Esto participa de la confección de asimetrías y a la llamada configuración fantasmática del capitalismo electrónico: actores, agentes, proyectos y fuerzas glocales están y no están en escena; las decisiones son tomadas en alguna parte y la mixtura de tiempos se amontonan, se acumulan impactando las vidas personales de lugares remotos, dirigiendo los órdenes locales y nacionales. Ese conjunto de rasgos asimilados con la caracterización de Arendt con respecto a las burocracias totalitarias modernas del "nadie es responsable", acompaña la carencia ética de los asuntos globales como el arriesgado soliloquio guerrero de la potencia hegemónica que amenaza con la ruptura de los frágiles equilibrios mundiales, desde el primer año de la década 2000.

Pero igualmente preocupante, es que dentro de los paisajes de pequeñas guerras locales o en los circuitos de la publicidad y las imágenes electrónicas, los espacios frecuentados o vividos suelen basar su permanencia en la opacidad de las indistinciones que nos habitúan paulatinamente, a actuar, pensar, escribir y recordar en la

"confusión de cuerpos y de lugares, de lo exterior y lo interior, de lo que es mudo y lo que está dotado de palabra, de lo que es esclavo y lo que es libre, de lo que es necesidad y lo que es deseo [con el riesgo de] enfrentarnos una y otra vez con la soledad y el mutismo allí donde lo que esperábamos era compañía y palabras." (Agamben, 2001 [1996]: 115)

De esas zonas de indeterminación rutinizadas con la modernidad global, la memoriación encara también una semejante ambigüedad de destino: se desliza en la espiral de la memorización codificada y decodicadora y en el exhaustivo inventario y registro automatizado del historial de las individuaciones: i.e., cada persona fenotípicamente identificada por las tecnologías antropométricas. Asimismo las memorias colectivas se confrontan con su banalidad (en un correspondiente auge de la "sociedad del espectáculo", volcada en la superficie por el análisis de Debord), que en última instancia es el menosprecio de los cuerpos vivientes y la banalización de la muerte. Si la división entre vida y muerte marcaba las fronteras significativas de la vida social y la memoria correspondió, en algún sentido, al pacto que los vivientes propusieron respecto a sus muertos, esa banalización incide directamente en decremento del valor por la vida.

Cuentan los versos de Jorge Luis Borges, en su poema "Límites",:

Si para todo hay término y hay tasa

Y última vez y nunca más y olvido

¿quién nos dirá de quién, en esta casa,

sin saberlo, nos hemos despedido? (Borges, 1981 [1968]: 30).

Quién nos puede contar que estamos aquí y ahora, en nuestra única morada el mundo y nuestro cuerpo ( nuestro sitio y refugio más próximo) si no es esa frontera que escinde y separa esta vida vivible de la vida vivida por nuestros muertos. La primera activación de la memoria no confronta pues el pasado que fue con lo que es y acontece ahora; no es una simple supervivencia -de lo viejo sobre lo nuevo- un atavismo a tradiciones pasadas. Por el contrario enmedio de los desafíos actuales, recuperar el sentido de la memoria como reconstrucción del pasado en función del presente (como lo hiciera tardíamente famoso el sociólogo Maurice Halbwachs), es actualizar "la tradición [...] la 
necesidad que el pasado de los muertes ejerce sobre el presente de los vivos" (Namer, 2004: 349), puesto que la relación entre vida/muerte que cada sociedad específica e históricamente se ha dado, es el límite más allá del cual la vida de los otros puede volverse imprescindible. Memoriar (quizá decir memoriar) con apego a los umbrales que nos damos, es pues una tarea de hoy, un reconocimiento ético de la vidas dignas de ser vividas y un reconocimiento igual, de las muertes que no tendrían que haber acontecido.

Por los cuerpos sin vida dejados en los parajes, calles, tránsitos y desiertos....

\section{Referencias}

Agamben, Giorgio. 2003 [1995]. Homo Sacer. El poder soberano y la nuda vida, Valencia: Pre-textos (1a. reimp.).

Agamben, Giorgio. 2001 [1996]. "En este exilio. Diario italiano 1992-94", Medios sin fin. Notas sobre la política, Valencia: Pretextos, pp. 101-118.

Aguiluz Ibargüen, Maya, 2005. "Cuerpos y espacios. Cronotopías del presente" en Guadalupe Valencia (coord.), Tiempo y Espacio: Miradas Múltiples, México D.F.: Centro de Investigaciones Interdisplinarias en Ciencias y Humanidades(CEIICH)-UNAM, (en prensa).

Arendt, Hannah. [1971] 1995. "El pensar y las reflexiones morales", De la historia a la acción, Barcelona: Paidós/I.C.E.-Universidad Autónoma de Barcelona.

Bachelard, Gaston, 1975 [1958]. Poéticas del Espacio, México D.F., Fondo de Cultura Económica.

Bardela, Claudio, 2002. "Pilgrimages of the Plagued: AIDs, Body and Society", Body and Society, vol 8, núm. 2, pp. 79-105

Báez Rubí, Linda. 2002 "El arte de la memoria y la emblemática", en Bárbara Skinfill Nogal y Eloy Gómez Bravos (eds.), Las dimensiones del arte emblemático, Zamora: El Colegio de Michoacán-Consejo Nacional de Ciencia y Tecnología, pp. 319-327.

Benjamin, Walter. 1967 [1955]. "Sobre algunos temas en Baudelaire", Ensayos escogidos, Buenos Aires: Ediciones Sur.

Bourdieu, Pierre. 2002 [1979]. La distinción. Criterio y bases sociales del gusto, México D.F.: Taurus.

Bordo, Susan, 2003 [1993]. "The Slender Body and Other Cultural Forms", Unbeareable Weight. Feminism, Western Culture and the Body, Berkeley-LA-Londres: Universitiy of California Press.

Borges, Jorge Luis. 1981 [1968]. "Límites", Nueva antología personal México D.F.: Siglo XXI, pp. 301.

Bugdeon, Shelley, 2003. "Identity as an Embodiment Event", Body and Society, vol 9, núm. 1, marzo, pp. 35-56. 
Casey, Edward S. 1997. The Fate of Place. A Philosophical History, Berkeley-Los Angeles-Londres: University of California Press.

Derrida, Jacques, 1998 [1986]. "Mnemosyne", Memorias de Paul de Man, Barcelona: Gedisa, pp. 1556.

Foucault, Michel. 1979. Discipline and Punish; The Birth of the Prison, Parte III, Nueva York, Vintage/Random House.

Foucault, Michel 1983. "Nietzsche, la genealogía, la historia", El discurso del poder, selección y presentación de Oscar Terán, México D.F., Folios.

Foucault, Michel 1984. "What is Enlightenment?", Paul Rabinow (ed.), The Foucault Reader, Nueva York, Macmillan.

Foucault, Michel 1996. Historia de la sexualidad. vol I. La voluntad de saber, México D.F. Siglo XXI.

Game, Ann, 1996, "Time, Space and Memory", en Scott Lash, R. Robertson, et.al, Global Modernities, Londres: Sage.

Hallbwachs, Maurice. 1968 [1950]. La mémoire collective, París: Presses Universitaires de France. [Hay reedición en francés de 1997].

Harvey, David, 1999, "The Body as Referent", The Hedgehog Review. Vol. 1, núm. 1, http: //www.virginia. edi/iasc/HH/fall99/HarBody.Vol.1.html

Hernández Sánchez, Domingo, 2003. “La cultura oral electrónica. Cuerpos, hackers y virus”, en

Irigaray, Luce. 1998 [1997]. Ser dos, México D.F.-Buenos Aires-Barcelona: Paidós.

Joxe, Alain 1999. La ciencia de la guerra y la paz, Colec. Umbrales, México D.F.: CEIICH-UNAM.

Kellner, Douglas, 1995. Media Culture: Culture Studies, Identity and Politics Between Modern and Postmodern, Londres y Nueva York: Routledge.

MacNaghten, Phil y John Urry, 1998. Contested Nature, Londres: Sage.

Namer, Gérard, 2004. "Postfacio" a Maurice Halbwachs, Los marcos sociales de la memoria, Barcelona: Anthropos.

Payne, Michael, 2002 [1998].“Cuerpo”, en Michael Payne (comp.), Diccionario de Teoría Crítica y Estudios Culturales, México D.F.-Buenos Aires-Barcelona: Paidós, pp. 119-120.

Ricouer, Paul 2003 [2000]. La memoria, la historia, el olvido, Madrid: Trotta.

Sigerist, Henry E. 1987 [1943]. Civilización y enfermedad, México D.F., Fondo de Cultura EconómicaInstituto Nacional de Salud Pública.

Simmel, Georg, 1986 [1908]. Sociología 2. Estudios sobre las formas de socialización, Madrid: Alianza Editorial.

Tábora, Rocío, 2001. Desde nuestros cuerpos hacia una nueva lectura de la política, la democracia y la sexualidad en Centroamérica, Tegucigalpa: Programa de las Naciones Unidas para el 
Desarrollo (PNUD), Colec. Cuadernos de Desarrollo Humano Sostenible, núm 3. [http:://www.undp.un.hn]

Wajcman, Gérard, 2001 [1998], El objeto del siglo, Buenos Aires: Amorrortu.

\section{Formato de citación}

Aguiluz, M. (2004). Memoria, lugares y cuerpos. Athenea Digital, 6. Disponible en http://antalya.uab.es/athenea/num6/aquiluz.pdf

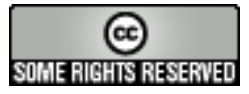

Este texto está protegido por una licencia Creative Commons.

Usted es libre de copiar, distribuir, exhibir y comunicar la obra bajo las siguientes condiciones:

Reconocimiento: Vd. debe reconocer y dar crédito al autor original.

NoComercial. Vd. no puede utilizar esta obra para fines comerciales.

NoDerivados. Vd. no puede alterar, transformar, o añadir nada a esta obra.

\section{Resumen de licencia}

Texto completo de la licencia 